\title{
Miscellany
}

\section{CCST Psychotherapy Training Guides}

Trainees contemplating embarking on a single or dual Certificate of Completion of Specialist Training in psychotherapy have 16 College approved training programmes to chose from. To aid them and inform tutors and psychotherapy trainers about the different programmes, we have asked training programme directors to write succinct descriptions of the aims of their training, and the implementation and resources available. The first issue of the compilation is now available. Psychotherapy programme directors and college tutors will have a copy. Copies are also available from the HSTC Office at the College. The compilation will be updated for 1999.

\section{New publications}

Acute Psychosis, Schizophrenia and Comorbid Disorders, edited by Alan Lee, is the first volume of a series bringing together popular articles from the journal Advances in Psychiatric Treatment. The articles have been updated to provide systematic, authoritative and well-referenced accounts of key clinical topics relating to modern therapeutic practice. While primarily aimed at senior psychiatric trainees, many of the articles will be of interest to other mental health professionals. Copies will be available from late summer at the Book Sales Office, Royal College of Psychiatrists, 17 Belgrave Square, London SW1X 8PG, priced £15.00 (Telephone: 0171235 2351 ext. 146).

Titles in Autism is a comprehensive new bulletin published by the National Autistic Society. This valuable resource allows those interested in autism to follow-up references from a wide range of academic journals. Areas covered include biochemical, medical, psychological, educational and social care aspects of autism and related and associated disorders. Information about international courses and conferences is also provided. Annual subscription rates: $£ 12.90$ (UK) and $£ 15.90$ (overseas). For further information: National Autistic Society, 393 City Road, London EC1V 1NE (Telephone: 0171903 3593, Fax: 0171833 9666, e-mail: nas@clus1.ulcc.ac.uk).

MIND have launched a new booklet How to Cope with Sleep Problems. The booklet discusses the many possible causes of disturbed sleep ranging from unsuitable temperature and noise levels, to excess caffeine or alcohol, through to more serious psychological factors such as stress and anxiety. The booklet is available from MIND Publications, 15-19 Broadway, Stratford, London E15 4BQ, priced £l plus a 38p A5 sized SAE (Telephone: 0181519 2122). 